\title{
Modified way of applying a tie-over dressing
}

Sir,

In addition to good contact between the graft and the bed and immobilisation, perfect edge to edge contact is important for acceptance of full thickness graft. Depending on the site and the surface area involved, different techniques have been proposed to immobilise the graft; tie-over dressing is one such technique. ${ }^{[1,2]}$ We propose a modified technique of applying tie-over dressing.

\section{TECHNIQUE}

After the required graft is harvested and the donor area closed, the graft is laid over the bed. A continuous running horizontal mattress suture is used to get good

edge to edge approximation [Figure 1a]. After every 


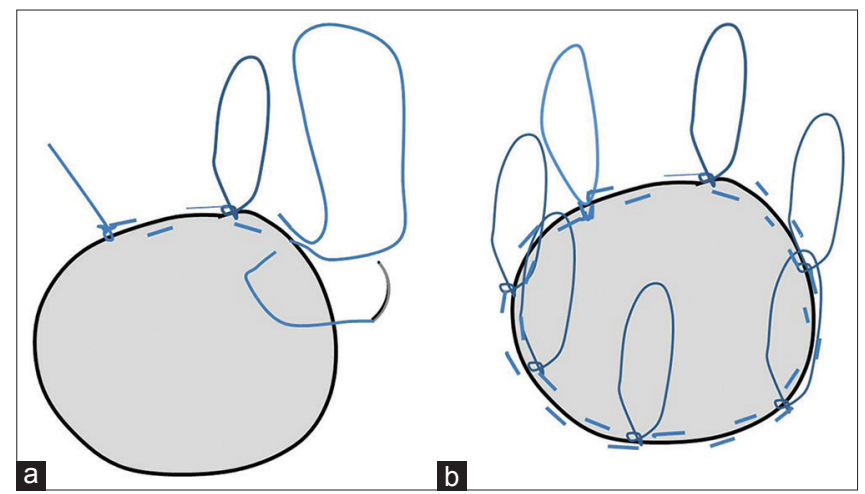

Figure 1: (a) After applying full thickness graft over the raw area, the graft is secured in place with continuous horizontal mattress sutures. At regular intervals (depending on predicted number of tie overs) a knot is tied with long loop of thread on one side. (b) The suturing is continued circumferentially keeping these knots with longer loops on one side at regular intervals
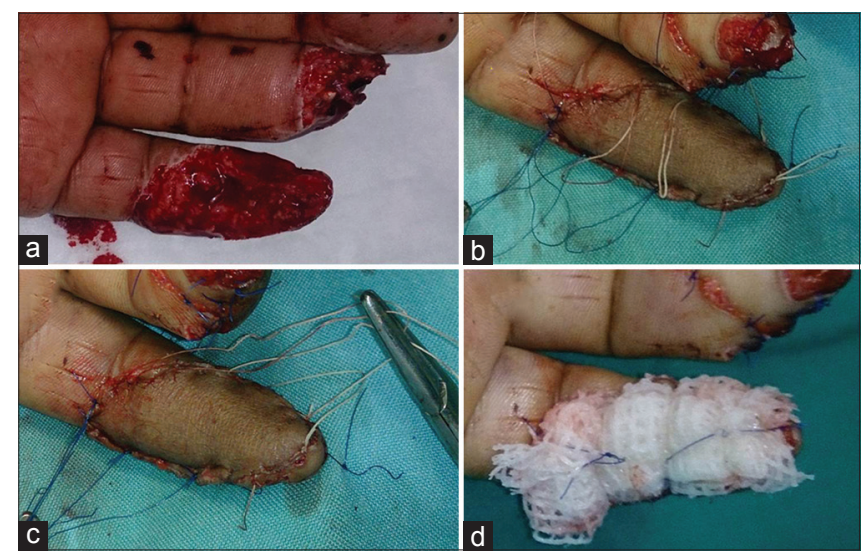

Figure 3: (a) A 63-year-old male sustained injury to his ring and little fingers. Little finger had volar soft tissue loss but the vital structures had adequate cover. (b) The defect was debrided and covered with full thickness graft from the inner aspect of the same arm. The graft is secured in place with continuous running horizontal mattress sutures with knots tied at regular intervals. One loop of the knot is kept longer. (c) After completing suturing, the loops are opened from one side to get sutures for tying over the dressing

(d) Completed tie over dressing. Ring finger defect was covered with a V-Y advancement flap

few bites, a knot is tied keeping an appropriately sized loop of the suture on one side [Figure 1a]. The suturing is continued in this manner, all around the graft and loops are kept at regular intervals [Figure 1b]. The number of loops required and their position (so that they lie opposite to each other) can be judged as the suturing is in progress. Once the suturing is complete, the loops are opened at one end with suture cutting scissors [Figure 2a]; this will double up the length of the thread available for tying over. The wound is then covered with Vaseline gauze and fluffy gauze dressing. The threads are then tied over this dressing to apply even pressure over the graft to complete the dressing [Figure 2b].

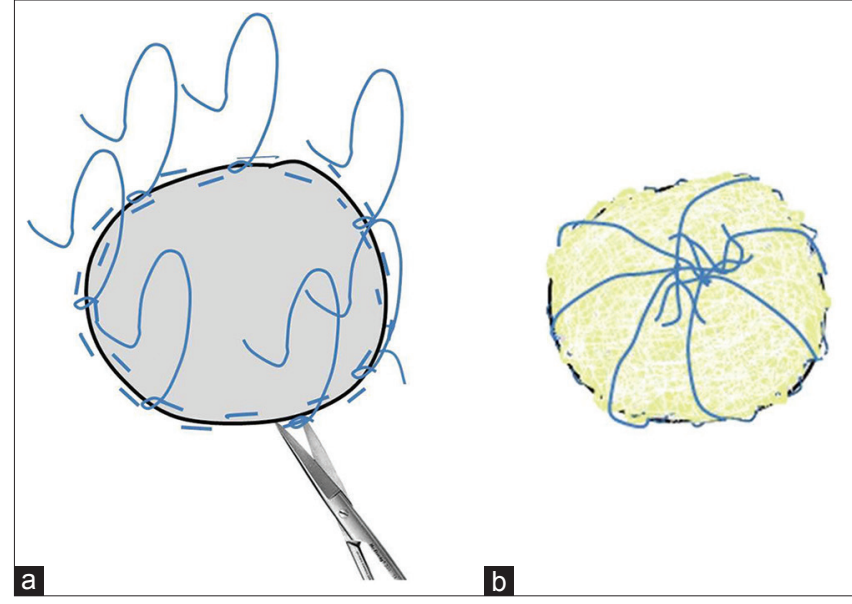

Figure 2: (a) After completing the suturing, one end of each loop is cut with scissors. This will double up the available thread length for tie over (one get used to the required length for comfortable tying very fast and the loop size is determined accordingly). (b) The threads are tied over the dressing to secure dressing in place and apply pressure avoiding collection underneath the graft. Some help is required only at this step otherwise a single surgeon can rapidly complete the dressing

\section{CASE}

A 65-year-old male sustained crush injury to his left ring and little fingers. Ring finger had sustained amputation through the distal phalanx while the little finger had lost the volar soft tissue without exposure of vital structures [Figure 3a]. The ring finger defect was covered with a V-Y advancement flap while the raw area over the little finger was covered with full thickness graft form the inner arm [Figure $3 \mathrm{~b}$ and $\mathrm{c}$. The graft was secured in place with running horizontal mattress sutures for good edge to edge contact with intermittent loops [Figure 3b], which are then opened [Figure 3c] for the tie-over dressing. The completed dressing is as in Figure 3d.

This technique is simple and reproducible. The operating surgeon can perform the procedure without need an assistant to cut the sutures. The running sutures save time and the suture material. It also makes the overall procedure much quicker. Horizontal mattress sutures ensure the best edge to edge approximation. On contrary to what one may feel, this suture does not have the constricting (purse string) effect of the continuous suture as it is interrupted by the knots in-between for the threads to be tied over. We have been regularly practicing this technique in our cases for the past 2 years, and it is very quick and convenient. 


\section{Financial support and sponsorship}

Nil.

\section{Conflicts of interest}

There are no conflicts of interest.

Rahul Krishnarao Patil, Ashok Raj Koul

Department of Plastic and Reconstructive Surgery, Sparsh

Hospital, Bengaluru, Karnataka, India

Address for correspondence: Dr. Rahul Krishnarao Patil, Sparsh Hospital, Opposite Commissioners Office, Infantry Road,

Bengaluru - 560 001, Karnataka, India. E-mail: doctrahul@yahoo.co.in

\section{REFERENCES}

1. Lapid O, Thomson HC. The speedo tie-over dressing. Ann Plast Surg 2005;54:215-7.

2. Joyce CW, Joyce KM, Kennedy AM, Kelly JL. The running barbed tie-over dressing. Plast Reconstr Surg Glob Open 2014;2:e137.

This is an open access article distributed under the terms of the Creative Commons Attribution-NonCommercial-ShareAlike 3.0 License, which allows others to remix, tweak, and build upon the work non-commercially, as long as the author is credited and the new creations are licensed under the identical terms.

\begin{tabular}{|l|l|}
\multicolumn{3}{c}{ Access this article online } \\
\hline Quick Response Code: & Website: \\
\hline & www.ijps.org \\
\cline { 2 - 2 } & \\
\hline
\end{tabular}

How to cite this article: Patil RK, Koul AR. Modified way of applying a tie-over dressing. Indian J Plast Surg 2016;49:124-6. 